\title{
ANATOMIA DA RAIZ ESCORA DE PHILODENDRON BIPINNATIFIDUM SCHOTT (ARACEAE) ${ }^{1}$
}

\author{
Wânia de Oliveira Vianna ${ }^{1,2}$ \\ Marli Kasue Misaki Soares ${ }^{3}$ \\ Beatriz Appezzato-da-Glória ${ }^{3,4}$
}

Recebido em 10/04/00. Aceito em 25/07/01.

\begin{abstract}
RESUMO - (Anatomia da raiz escora de Philodendron bipinnatifidum Schott (Araceae)). O imbé (Philodendron bipinnatifidum) é amplamente distribuído no Brasil. As plantas possuem raízes escoras, pelas quais se apóiam no suporte, e raízes de absorção, as quais crescem sob o solo e obtêm os nutrientes. Este estudo apresenta informações sobre a anatomia das raízes escoras enfatizando a organização do sistema vascular e a origem dos ductos resiníferos. Na região suberificada, as raízes eram amarronzadas e na porção apical eram esbranquiçadas. A partir do ápice radicular, foram retiradas amostras de $0,3 \mathrm{~cm}$ de comprimento totalizando $1,2 \mathrm{~cm}$. Da região suberificada, foram retiradas amostras com $0,5 \mathrm{~cm}$. As amostras foram fixadas em solução de Karnovsky, desidratadas em série etílica e infiltradas em resina glicol metacrilato. Na região situada entre 1,0 e 3,0mm do ápice radicular, a raiz escora possuía uma coifa plurisseriada cujas células apresentavam paredes anticlinais sinuosas. A protoderme era unisseriada. Os ductos de resina, de origem esquizógena, diferenciavam-se entre as células do meristema fundamental. O cilindro vascular apresentava-se lobado. Na região suberificada, a epiderme era substituída pelo súber estratificado, o parênquima cortical possuía várias camadas de células entre as quais ocorriam ductos resiníferos de origem esquizógena e muitos idioblastos secretores. O cilindro central possuía organização estelar "anômala" e desprovida de medula.
\end{abstract}

Palavras-chave - Philodendron, Araceae, anatomia, raízes aéreas, ductos resiníferos

\begin{abstract}
Prop root anatomy of Philodendron bipinnatifidum Schott (Araceae)). Imb (Philodendron bipinnatifidum), has a large distribution in Brazil. It produces aerial and subterranean roots. This study presents the anatomical description of the mature prop roots and analyzes the apical root meristem region $(1.0-3.0 \mathrm{~mm})$. The roots were brown except for the apical portion, which was white. Root segments measuring $0.3 \mathrm{~cm}$ in length were excised from aerial roots for a length of $1.2 \mathrm{~cm}$ starting from the root tip. Another $0.5 \mathrm{~cm}$ segment from the suberized region of the root, was also excised. The segments were fixed in Karnovsky solution, dehydrated in a graded ethanol series (10 to 100\%), and then embedded in glycol methacrylate resin. The apical root meristem region $(1.0-3.0 \mathrm{~mm})$, presented a many-layered root cap that consisted of sinuous anticlinal cell walls, compactly arranged. The protodermis was uniseriated. The resin ducts arose schizogenous among the fundamental meristem cells. The central cylinder exhibited conspicuous lobes. In suberized region, the epidermis was substituted by a stratified cork. The outer part of the cortex was arranged in relatively bigger intercellular spaces while the inner cortex presents 4 and 5 layers of cells arranged in radial files. The resin ducts and the secretory idioblasts occurred among cells of the cortical parenchyma. The central cylinder exhibited anomalous organization of vascular tissues with conspicuous lobes and a pith region was absent.
\end{abstract}

Key words - imb, Araceae, anatomy, aerial roots, resin ducts

\footnotetext{
${ }^{1}$ Parte da tese de doutorado da primeira autora

${ }^{2}$ Pós-graduada do Departamento de Biofarmacognosia - Faculdade de Ciências Farmacêuticas, São Paulo, Brasil

${ }^{3}$ Departamento de Ciências Biológicas, ESALQ/USP, C. Postal 9, CEP 13418-900, Piracicaba, SP, Brasil

(e-mail: bagloria@carpa.ciagri.usp.br)

${ }^{4}$ Bolsista de Pesquisa do CNPq
} 


\section{Introdução}

No Brasil, as Araceae são utilizadas especialmente como ornamentais. Entre as espécies nativas utilizadas em projetos paisagísticos pode ser citada Philodendron bipinnatifidum.

Apesar desta espécie ser reconhecida como planta tóxica, a medicina popular temse utilizado desta planta em alguns casos patológicos, tais como: erisipela, inflamações reumáticas, entre outros (Balbach 1979). O uso popular das raízes aéreas como contraceptivo referido por Balbach (1979) motivou o estudo deste órgão.

As raízes em Araceae são sempre adventícias e raízes dimórficas são freqüentemente encontradas em lianas hemi-epífitas como é o caso de P. bipinnatifidum (French 1997). Nesta espécie, existe uma clara distinção entre as raízes aéreas escoras pelas quais as plantas se apóiam no suporte e as raízes subterrâneas de absorção as quais crescem sob o solo e obtêm os nutrientes (Mayo 1986).

Hinchee (1981) propôs três denominações para as raízes aéreas de Monstera deliciosa: raízes aéreas, raízes aéreas-subterrâneas (surgindo a partir de um ápice radicular aéreo e que tenha penetrado no solo) e raízes laterais subterrâneas surgindo a partir de uma raiz aérea-subterrânea.

Algumas descrições sobre a anatomia das raízes escoras adultas de $P$. bipinnatifidum são apresentadas por Porsch (1911) e Engler (1912). Porém, no presente estudo, ao se analisar a estrutura adulta da raiz escora desta espécie, foi verificado que várias interpretações somente seriam possíveis se a região do meristema apical da raiz fosse analisada. Portanto, neste estudo são apresentadas informações sobre a anatomia das regiões apical e suberificada das raízes aéreas enfatizando a organização do sistema vascular e a origem dos ductos resiníferos.

\section{Materiais e métodos}

O material botânico utilizado no presente trabalho foi coletado no Parque da "Escola Superior de Agricultura Luiz de Queiroz" (ESALQ), da Universidade de São Paulo, em Piracicaba, São Paulo, Brasil. O material foi identificado por especialista e depositado no Herbário do Departamento de Botânica do Instituto de Biociências da Universidade de São Paulo, SPF 128.461.

As análises anatômicas foram realizadas em raízes aéreas (segundo a classificação de Hinchee 1981). As raízes eram amarronzadas, exceto na porção apical, a qual era esbranquiçada. Foram amostradas raízes com 5 e $42 \mathrm{~cm}$ de comprimento. De cada raiz, foram retirados fragmentos de $0,3 \mathrm{~cm}$ de comprimento, obtidos a partir do ápice radicular, totalizando $1,2 \mathrm{~cm}$. Na região mediana da raiz, foram retiradas amostras de $0,5 \mathrm{~cm}$. As amostras foram fixadas em solução de Karnovsky (Karnovsky 1965), desidratadas em série alcoólica-etílica, infiltradas com a resina glicol-metacrilato e seccionadas seriadamente nos planos transversal e longitudinal. As seções, com $5 \mathrm{~mm}$ de espessura, foram coradas com azul de toluidina (Sakai 1973) e montadas em resina sintética "Entellan". As fotomicrografias feitas em fotomicroscópio NIKON AFX-DX, com as escalas micrométricas fotografadas e ampliadas nas mesmas condições ópticas utilizadas.

Os testes histoquímicos foram realizados em seções de material não fixado, obtidas a mão-livre com auxílio de lâmina de barbear. A presença de compostos fenólicos foi analisada pelo cloreto férrico (Johansen 1940); o amido foi visualizado pelo emprego de cloreto de zinco iodado (Strasburger 1913); as substâncias lipofilicas pelo Sudan IV (Jensen 1962) e os polissacarídeos pelo azul de metileno (Johansen 1940).

\section{Resultados e discussão}

Nas raízes escoras de $P$. bipinnatifidum, na região situada entre 1,0 e 3,0mm do ápice radi- 


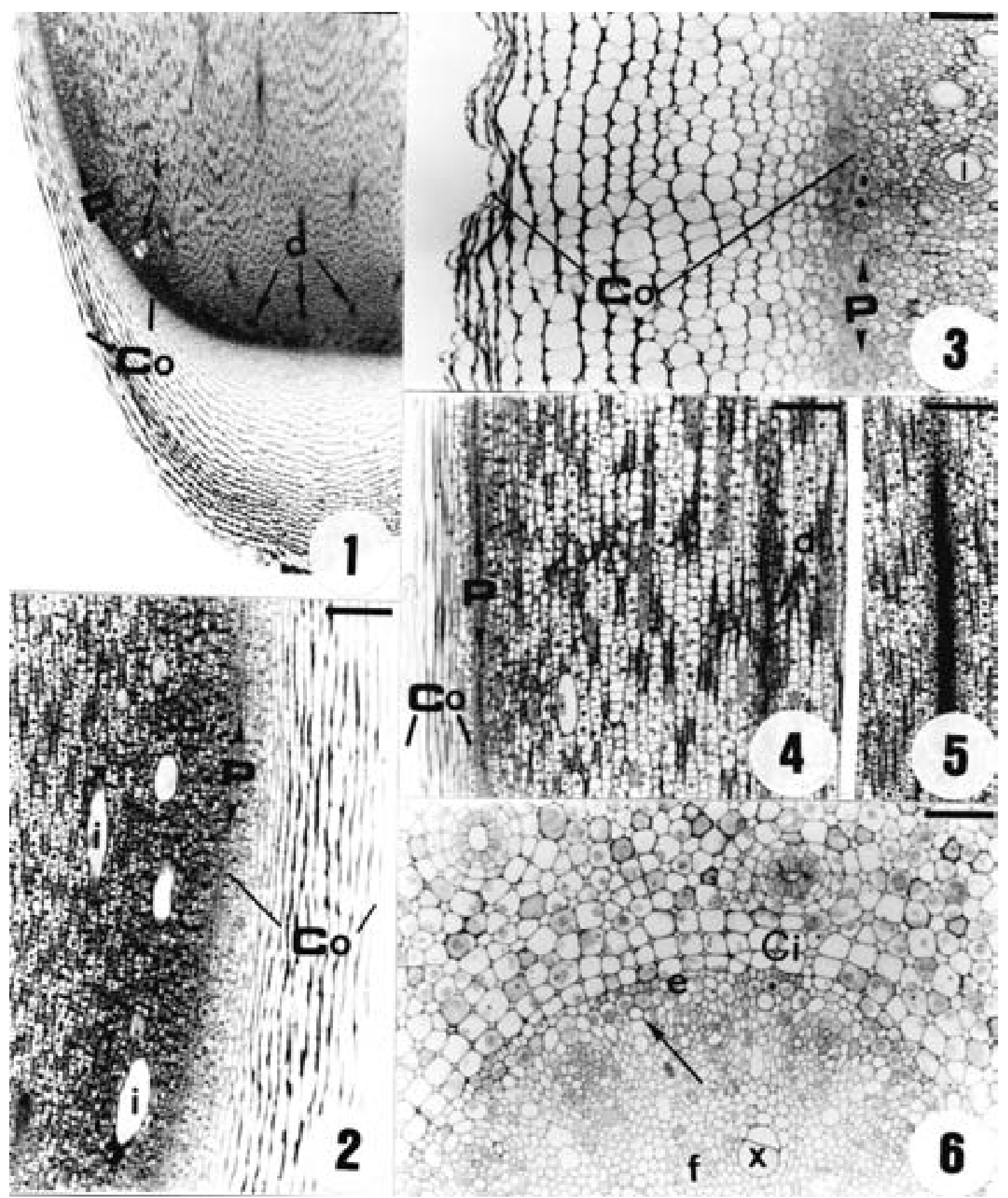

Figuras 1-6. Seções longitudinais e transversais da raiz aérea de Philodendron bipinnatifidum na região situada entre 1,0 e 3,0mm do ápice radicular. 1-3. A coifa (Co) é plurisseriada; idioblastos secretores (i) e ductos (d) em diferenciação; a protoderme (p) é unisseriada. 4-5. Diferenciação dos ductos em seção longitudinal. 6. Córtex interno (Ci) apresentando células em arranjo radial e endoderme (e) ainda não diferenciada. No cilindro vascular, além dos pólos de protoxilema em diferenciação (seta) alternados com os cordões de floema, já são observados os elementos de vaso (x) e os elementos floemáticos (f) imaturos que ocorrem distribuídos aleatoriamente no restante do cilindro vascular. 1 . Barra $=552 \mathrm{~mm} ; 3$, 6. Barra $=102 \mathrm{~mm} ; 2,4,5$. Barra $=205 \mathrm{~mm}$. 
cular, observam-se os tecidos em fase inicial de diferenciação (Fig. 1-5).

A coifa, em seção transversal (Fig. 3) possui cerca de nove camadas de células com paredes anticlinais sinuosas e, mais internamente, três a quatro camadas de células menores e isodiamétricas. A organização da coifa (Fig. 1-4), em corte transversal (Fig. 2, 3), fornece uma falsa impressão de tratar-se de um velame pluriestratificado. Matheus et al. (1997) também observaram em Philodendrum lacerum a presença de uma coifa que parecia uma falsa epiderme múltipla.

Segundo Engler (1912), as raízes adventícias jovens de Philodendron possuem velame uni ou bisseriado, o qual é delicado e de curta duração. Na espécie em estudo o que se observa é uma protoderme unisseriada (Fig. 4).

As primeiras camadas do córtex apresentam células também isodiamétricas, porém providas de citoplasma denso, com núcleo e nucléolo proeminentes. No córtex, entre as células do meristema fundamental, observam-se idioblastos secretores em diferenciação (Fig. 1-3) e ductos resiníferos em várias fases de desenvolvimento (Fig. 4-12).

Os ductos são de origem esquizógena, tendo em vista que o lume é formado pela separação das células (Fig. 4, 5, 7,8) que constituirão a camada epitelial. A camada epitelial, constituída de células com citoplasma denso, núcleo e nucléolo proeminente e paredes delgadas, é circundada por duas a três camadas de células de paredes delgadas que não apresentam citoplasma denso (Fig. 9-12).

A última camada do córtex, a endoderme, ainda não apresenta estrias de Caspary (Fig. 6). O cilindro vascular já se apresenta lobado como pode ser visualizado na raiz madura (Fig. 15) e, além dos pólos de protoxilema em diferenciação alternados com os cordões de floema, já são observados os elementos de vaso e os elementos floemáticos imaturos, que ocorrem distribuídos aleatoriamente no restante do cilindro vascular (Fig. 6). Na raiz escora adulta (Fig.
13), que se caracteriza pela coloração amarronzada, a epiderme é substituída pelo súber estratificado. Este tecido apresenta as quatro primeiras camadas de células com as paredes espessas e lignificadas.

Nas camadas seguintes, as células possuem paredes suberizadas e o grau de obliteração das paredes periclinais aumenta no sentido centrífugo, ou seja, as células recém-formadas possuem paredes menos obliteradas que aquelas subjacentes às camadas esclerificadas (Fig. 13).

No parênquima cortical, observam-se células dividindo no plano periclinal, originando o súber estratificado (Fig. 13). As primeiras camadas esclerificadas do súber em $P$. bipinnatifidum, provavelmente, persistam por um período mais longo de tempo, como ocorre com as células epidérmicas esclerificadas de muitas monocotiledôneas cujo único tecido de proteção é a epiderme (Mauseth 1995).

O córtex remanescente é constituído de várias camadas de células, muitas das quais acumulam amido, arranjadas deixando amplos espaços intercelulares (Fig. 13), com exceção das últimas camadas, que apresentam arranjo compacto (Fig. 16). Entre as células do parênquima cortical, ocorrem ductos resiníferos (Fig. 13, 16), idioblastos contendo cristais de oxalato de cálcio na forma de drusas ou rafídeos e idioblastos secretores (Fig. 13) de conteúdo heterogêneo, que reage positivamente aos testes histoquímicos para compostos fenólicos, mucilagens e substâncias de natureza lipídica. A endoderme (Fig. 17) apresenta células com paredes espessadas em "O" lignificadas, entre as quais ocorrem células de passagem.

A organização do cilindro central em lobos conspícuos (Fig. 15) é similar à descrita para o caule de Bauhinia e para certos caules de uva (Mauseth 1995). Segundo o autor, nesses caules ocorre uma variação na atividade cambial, onde alguns setores do câmbio são muito ativos enquanto em outros são quase totalmente inativos, de modo que o caule cresce em apenas algumas direções. Este tipo de crescimento se- 


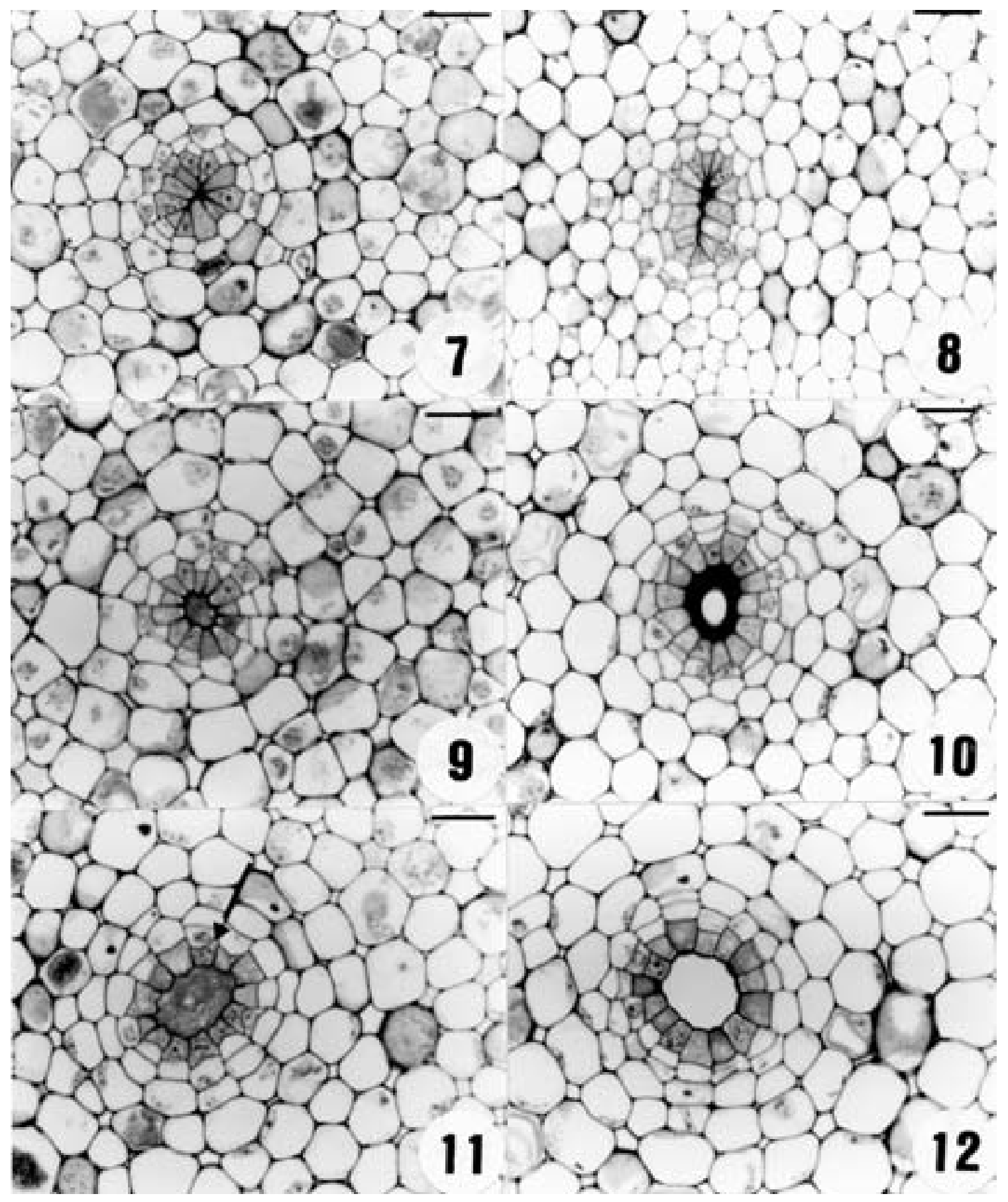

Figuras 7-12. Seções transversais da raiz aérea de Philodendron bipinnatifidum, na região situada entre 1,0 e 3,0mm do ápice radicular, mostrando as várias fases de desenvolvimento dos ductos resiníferos ao longo de todo o córtex. 7-8. Formação do lume do ducto pela separação das células que constituirão a camada epitelial, evidenciando sua origem esquizógena. 9-12. Formação das camadas de células de parede delgada que circundam o epitélio secretor (barras = $53 \mathrm{~mm})$. 


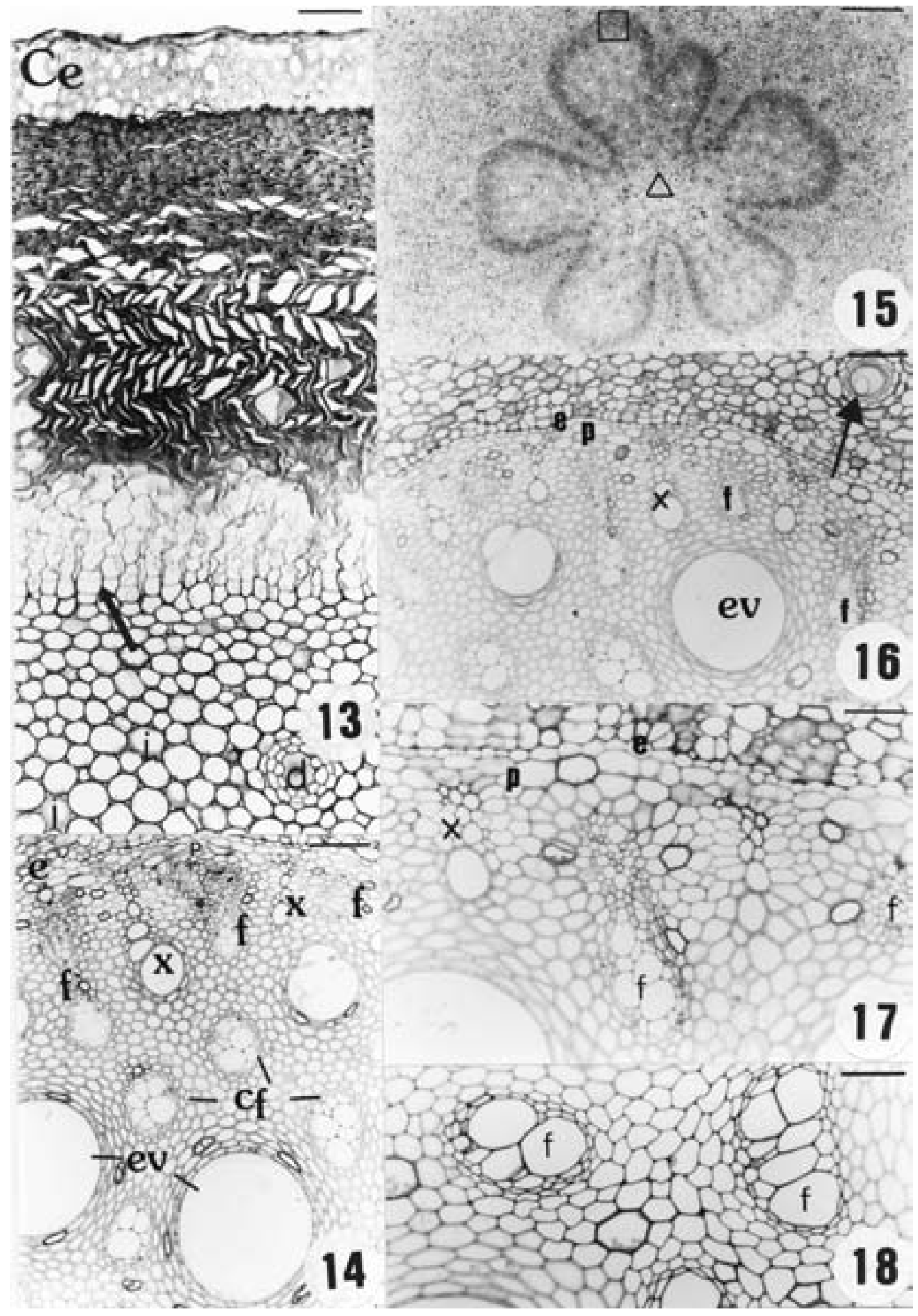


Figuras 13-18. Seções transversais da raiz aérea madura de Philodendron bipinnatifidum. 13. Primeiras camadas do súber com células de paredes espessas e lignificadas (Ce). As camadas seguintes apresentam células com paredes suberizadas cujo grau de obliteração das paredes periclinais aumenta no sentido centrífugo. Observar as divisões periclinais nas células do parênquima cortical (seta), a presença de ductos resiníferos (d) e de idioblastos de conteúdo heterogêneo (i)

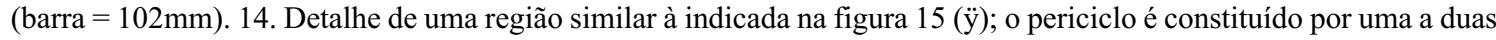
camadas de células; na periferia do cilindro vascular os cordões de floema e xilema primários ocorrem alternadamente (f, $\mathrm{x})$. Além destes cordões periféricos de floema e xilema alternados, observam-se elementos de vasos isolados de diâmetro amplo (ev), distribuídos aleatoriamente entre conjuntos de células floemáticas (cf) também de diâmetro amplo (barra = $205 \mathrm{~mm}$ ). 15. Visão geral do cilindro vascular organizado em lobos conspícuos. Os setores indicados pelo ÿ e pelo D, na estrutura adulta, apresentam os tecidos mostrados nas figuras 14, 16, 17 e 18, respectivamente (barra $=552 \mathrm{~mm}$ ). 16. A seta indica a secreção num ducto resinífero do córtex; endoderme (e), periciclo (p), cordões periféricos de floema (f) e xilema (x) alternados e elementos de vasos isolados de diâmetro amplo (ev) (barra $=205 \mathrm{~mm})$. 17. Detalhe da endoderme (e), periciclo (p). Os cordões de floema (f) ora são curtos ora são longos e ocorrem alternadamente com o xilema primário $(\mathrm{x})($ barra $=102 \mathrm{~mm})$. 18. Na porção central $(\mathrm{D})$, aparecem conjuntos de células floemáticas também de diâmetro amplo (f), rodeadas por células de paredes delgadas (barra $=102 \mathrm{~mm}$ ).

cundário variante é adaptativo e está relacionado à condutividade e à flexibilidade (Mauseth 1995). Embora na espécie em estudo não haja a instalação de um câmbio vascular, a organização do estelo em lobos considerada "anômala" por Mayo (1986), pode estar relacionada com a função da raiz escora, que necessita flexibilidade durante o desenvolvimento.

O periciclo é constituído por uma a duas camadas de células (Fig. 17). Na região externa do cilindro vascular, os cordões de floema e xilema primários ocorrem alternadamente (Fig. 16-17). Os cordões de floema ora são curtos ora são longos (Fig. 16-17), conforme descrito em Calathea lindberguii por Uliana (1999). Além destes cordões periféricos alternados de floema e xilema, o restante do cilindro central é constituído por elementos de vaso de diâmetro amplo isolados distribuídos aleatoriamente entre cordões floemáticos, cujos elementos de tubo crivado têm diâmetro amplo (Fig. 14, 17-18).

De acordo com Tomlinson \& Fisher (1998), os elementos de vaso amplos atuam no estoque e no transporte rápido de água. Entre os tecidos vasculares, ocorrem laticíferos visualizados em seções transversais como células de paredes mais densas e conteúdo granulado (Fig. 17,18). As demais células do cilindro vascular exibem paredes lignificadas (Fig. 17) exceto na porção central (Fig. 18).
Não há, portanto, uma medula parenquimática como propôs Porsch (1911) para as raízes escoras desta espécie.

\section{Agradecimentos}

À Dra. Cássia M. Sakuragui, Departamento de Botânica, Universidade Estadual de Maringá, pela identificação do material botânico.

\section{Referências bibliográficas}

Balbach, A. 1979. A flora nacional na medicina doméstica: plantas medicinais 2. 6. ed. A edificação do lar, Rio de Janeiro.

Engler, A. 1912. Araceae-PhilodendroideaePhilodendreae. Allgemeiner Teil, Homalomeninae und Schismatoglottidinae. Pp. 1-134. In: A. Engler (Ed.), Das Pflanzenreich 55 (IV. 23 Da).

French, J. C. 1987. Systematic occurrence of a sclerotic hypodermis in roots of Araceae. American Journal of Botany 74: 891-903.

French, J. C. 1997. Vegetative anatomy. Pp. 09-24. In: S. J. Mayo; J. Bogner \& P.C. Boyce (Eds.) The genera of Araceae. Royal Botanic Gardens, Kew.

Hinchee, M. A. W. 1981. Morphogenesis of aerial and subterranean roots of Monstera deliciosa. Botanical Gazette 142: 347-359.

Jensen, W. A. 1962. Botanical histochemistry: principle and practice. W.H. Freeman, San Francisco.

Johansen, D. A. 1940. Plant microtechnique. MacGraw-Hill Book Company, New York. 
Karnovsky, M. J. 1965. A formaldehyde-glutaraldehyde fixative of high osmolality for use in electron microscopy. Journal of Cell Biology 27: 137-138.

Matheus, M.; Wee, M. L. \& Ho, K. K. 1997. Growth and development of aerial roots of a tropical ornamental, Philodendron lacerum. Journal of Horticultural Science 72: 27-34.

Mauseth, J. D. 1995. Botany - an introduction to plant biology. Sauders College Publishing, Philadelphia.

Mayo, S. J. 1986. Systematics of Philodendron Schott (Araceae) with special reference to inflorescence characters. Ph.D. thesis. Univ. Reading, UK.

Porsch, O. 1911. Die Anatomie der Nähr - und Haftwurzeln von Philodendron selloum C. Koch. Denkschr. Akad. Wiss. Wien. Math - naturwiss. KI. 79: 390-451.

Sakai, W. S. 1973. Simple method for differential staining of paraffin embedded plant material using toluidine blue O. Stain Technology 48 (5): 247249.

Strasburger, E. 1913. Handbook of practical botany. 7. ed. George Allen, London.

Tomlinson, P. B. \& Fisher, J. B. 1998. Stem vasculature in climbing monocotyledons: a comparative approach. Royal Botanic Gardens, Sydney.

Uliana, V. L. C. 1999. Morfo-anatomia de espécies de Marantaceae do núcleo Picinguaba, Ubatuba, SP, Brasil. Dissertação de Mestrado. UNESP, Rio Claro. 